\title{
MEMBERDAYAKAN HIGHT ORDER THINKING SKILLS (HOTS) MELAUI MODEL DISCOVERY BASED UNITY of SCIENCES (DBUS)
}

\author{
Nur Khasanah \\ Jurusan Pendidikan Biologi UIN Walisongo Semarang
}

\begin{abstract}
The purpose of the research is to know the implementation of Discovery Based Unity of Sciences model in learning biology. The subjects of the study are students majoring in biology education of UIN Walisongo Semarang at first year 2017/2018. Research method using Research and Development $(R n D)$. Implementation of DBUS model there were 6 steps, ei: (1) Stimulation using local wisdom, (2) Problem statement, (3) Observation and Data collection, (4) Data Processing, (5) Verification base on religion (6) Implementation and awarenest. The $N$-gain value at UIN Walisongo obtained by the experimental class was 0.23 greater than the control group of 0.09. The results of statistical testing at the UIN Walisongo Semarang obtained the average value of the pretest was 2.45 and the average posttest score was 7.4167. The correlation between pretest posttest was $0.035<5 \%$ with a $t$ value $=9.332$ with a sig value of $0.000<0.05$. The $T$ test on the DBUS model at UIN Walisongo from the correlation results on T count is 0.862, showing the results of the correlation on the influence of DBUS model on the increase in PRB is High. The size effect of the DBUS model is categorized as having a large effect because it has a value of $d>0.8$ that is $d$ $=0.93$.
\end{abstract}

Keywords: Integration Of Sciences, DBUS Model, Critical Thinking Skill, $P R B$ 


\begin{abstract}
Abstrak
Tujuan penelitian ini untuk mengetahui implementasi model Discovery Based Unity of Sciences dalam belajar biologi. Subyek penelitian ini adalah mahasiswa jurusan pendidikan biologi UIN Walisongo Semarang tahun pertama th. 2017/2018. Metode penelitian menggunakan Research and Development (RnD). Implementasi Model DBUS melaui 6 langkah, yaitu: (1) Stimulation using local wisdom, (2) Problem statement, (3) Observation and Data collection, (4) Data Processing, (5) Verification base on religion (6) Implementation and awarenest. Nilai $N$-gain di UIN Walisongo diperoleh kelas eksperimen sebesar 0,23 lebih besar dibandingkan dengan kelompok kontrol sebesar 0,09. Hasil pengujian statistik di UIN Walisongo Semarang diperoleh nilai rata-rata pretest adalah 2,45 dan nilai rata-rata posttest adalah 7,4167. Korelasi antara pretest postest adalah 0,035 < 5\% dengan nilai $t_{\text {hitung }}=9,326$ dengan nilai sig 0,000 $<0,05$. Uji $T$ test pada model DBUS di UIN Walisongo dari hasil korelasi pada T hitung adalah 0,862, menunjukan hasil kolerasi pada pengaruh model DBUS terhadap peningkatan PRB mahasiswa UIN Walisongo adalah Tinggi. Efek size dari model DBUS mempunyai efek besar karena memiliki nilai $d>0,8$ yakni $d=0,93$
\end{abstract}

Kata Kunci: Integrasi Sains, Model DBUS, Keterampilan Berpikir Kritis, $P R B$

\title{
PENDAHULUAN
}

Tantangan dunia pendidikan pada era reformasi teknologi dan era revolusi industri 4.0 adalah penguatan karakter pada peserta didik. Penguatan karakter akan lebih efektif apabila dapat dilakukan secara lebih masif dalam pembelajaran di setiap mata pelajaran yang ada. Biologi merupakan salah satu mata kuliah Sains yang sangat mungkin untuk dikembangkan dengan model-model pembelajaran saintifik yang sekaligus dapat menguatkan karakter peserta didik. Pada era global, pendidikan di Indonesia perlu memperhatikan kebhinnekaan etnis, budaya, agama dan sosial (Liliasari, 2007).

Model pembelajaran DBUS (Discovery Based Unity of Sciences) sebagai hasil riset terkait pengembangan model pembelajaran merupakan model berbasis pada kesatuan ilmu yang dapat diimplementasikan pada kurikulum 2013. Melalui model $D B U S$ mahasiswa dapat memperoleh pengalaman langsung, sehingga dapat menambah kekuatan untuk menerima, menyimpan, dan menerapkan konsep yang telah dipelajarinya. Siswa terlatih untuk dapat menemukan sendiri berbagai konsep yang dipelajari secara menyeluruh (holistik), bermakna, otentik dan aktif. 
Pengembangan model DBUS untuk mengembangkan kemampuan mahasiswa untuk belajar secara konstruktif dan bermakna sehingga dapat mengembangkan kemampuan berpikir kritis. Berpikir kritis berarti menggunakan proses-proses mental, seperti memperhatikan, mengkategorikan, seleksi, menilai dan memutuskan (Dracup, 2012; Atilla et al, 2015).

Personal Religious Beliefs (PRB) adalah istilah yang digunakan untuk merujuk kepada pandangan, pendapat, sikap, dan pengetahuan yang dibangun oleh seseorang melalui interaksi dengan konteks sosio-budaya dalam sejarah hidup dan ditafsirkan sebagai agama yang dianut (Mansour, 2008; 2009). PRB mahasiswa penting untuk dikembangkan supaya dapat memahami peristiwa, pengalaman dan objek pada tingkat individu dan merupakan konstruksi sosial berdasarkan berbagai pengalaman hidup khususnya pada pengalaman religi sehingga belajar lebih bermakna (Gamal, 2012; Taskin, 2014). Belajar bermakna selain dapat menguasai aspek kognitif diharapkan dapat mengembangkan nilai religius siswa.

Pembelajaran biologi di UIN Walisongo Semarang belum seluruhnya menerapkan konsep kesatuan ilmu dalam bentuk integrasi nilai karakter dan keislaman dengan konsep materi. Hasil riset awal terhadap kemampuan pembelajaran pada mahasiswa menunjukkan mahasiswa kurang aktif dan kritis, dilihat dari partisipasi ketika mengikuti praktek, diskusi dan presentasi di kelas. Siswa masih kesulitan dalam mengintegrasi konsep biologi yang dipelajari dengan konsep pengetahuan yang lain menunjukkan PRB mahasiswa dipengaruhi oleh pendidikan sebelumnya dan lingkungan tempat tinggal siswa. Model DBUS berdasarkan riset terbukti efektif untuk memberdayakan ketrampilan berpikir kritis dan kemampuan personal religious beliefs sebesar $86 \%$ (Khasanah N. et al, 2016; 2017). Berdasarkan penelitian awal dan potensi masalah tersebut maka diperlukan implementasi model DBUS tersebut untuk diaplikasikan di kelas pendidikan. Bagaimana implementasinya di kelas perlu observasi dan penelitian.

\section{METODE PENELITIAN}

Metode penelitian menggunakan Research and Development (RnD). Implementasi Model DBUS melaui 6 langkah, yaitu: (1) Stimulation using local wisdom, (2) Problem statement, (3) Observation and Data collection, (4) Data Processing, (5) Verification base on religion (6) Implementation and awarenest. 


\section{HASIL DAN PEMBAHASAN}

\section{Implementasi Model DBUS}

Implementasi dari model DBUS mempunyai karakteristik melalui sintaksis. Sintaks dideskripsikan dalam urutan aktifitas dalam kegiatan pembelajaran. Model DBUS mempunyai enam langkah, meliputi: Stimulation Using Lokal Wisdom, Problem statement, Observation \& Data collection, Data Processing, Verification base on Religion, Generalization \& Awareness.

\section{Stimulation Using Lokal Wisdom}

Mahasiswa melakukan aktifitas pengenalan terhadap lingkungan masyarakat sekitar. Mahasiswa mengamati dan atau mendeskripsikan kejadian-kejadian atau permasalahan yang ditemui di lingkungan masyarakat sekitar kampus atau tempat tinggal mahasiswa baik langsung atau dari hasil pengamatan tentang Dasar pewarisan sifat dan Bioteknologi (Eksplorasi pendapat). Isu-isu yang berkembang terkait perkawinan masih saudara, halal-haram teknologi olahan pangan (alkohol dari tape, enzim pembuatan bumbu masak).

Keterampilan kritis mahasiswa dengan mendeskripsikan permaasalahan yang sedang terjadi lingkungan masyarakat. Menggali fenomena yang berkembang terkait konsep. Ekplorasi dilakukan secara berkelompok dengan mengemukakan masingmasing pendapat di dalam kelompoknya. Pada kelas kontrol ataupun ekperimen baik di UIN Walisongo ataupun di UIN Sunan Kalijaga mengalami peningkatan. Mahasiswa di kelas ekperimen mampu menyebutkan lebih banyak contoh dan mampu menginterpretasikan pendapatnya dalam kelompok sehingga kelas lebih aktif.

Dengan memanfaatkan fenomena dilingkungan, mahasiswa tertanam rasa empati dengan lingkungan disekitarnya sehingga PRB mahasiswa dapat lebih baik. Dengan demikian belajar lebih bermakna.

\section{Problem statement}

Mahasiswa melakukan kegiatan menemukan, merumuskan masalah masalah mengacu kepada sumber belajar dan high order thinking skills (HOTS). Mahasiswa mengisi lembar kerja yang sudah disediakan secara berkelompok. Mahasiswa menetapkan hipotesis dari permasalahan yang dikemukakan. 
Mahasiswa menyusun rencana eksperimen dalam bentuk lembar kerja mahasiswa secara berkelompok. Lembar kerja meliputi persilangan monohibrid dan dihibrid. Membuat tabel genotip dan fenotip yang kemungkinan terjadi.

Mahasiswa melakukan kajian ayat al Qur'an yang sesuai dengan pewarisan sifat. Dengan melakukan kajian ayat al Qur'an semakin meningkatkan keyakian mahasiswa bahwa Allah SWT telah mengatur dengan segala sesuatunya untuk manusia.

\section{Observation \& Data collection}

Mahasiswa melakukan observasi nilai-nilai tradisional (bibit, bebet dan bobot) dan bioteknologi konvensional (pembuatan tape, tempe, oncom) yang dapat dipakai sebagai sumber belajar. Mahasiswa mengumpulkan berbagai informasi yang relevan dan membaca literatur, mengamati objek, wawancara dengan nara sumber. Mahasiswa mengumpulkan pendapat masyarakat, tokoh agama (misalnya; MUI), kajian kitab (tafsir dan figih nya) terkait permasalahan dan konsep yang dipelajari. Mahasiswa melakukan praktikum dengan menjawab pertanyaan dan membuktikan hipotesis melalui jawaban pertanyaan dalam laporan kerja mahasiswa.

Keterampilan berpikir kritis mahasiswa yang terlihat meliputi kegiatan pengamatan, pengumpulan data, praktikum, diskusi kelompok, dan melakukan evaluasi. Sedangkan PRB yang ditekankan adalah mahasiswa mampu menerapkan sifat-sifat Rasululloh SAW (Sidiq, tabligh, fathonah, dan amanah) ketika kegiatan praktikum.

\section{Data Processing}

Mahasiswa melakukan pengolahan data, menganalisis hasil dan menginformaskan hasil ekperimen yang telah diperoleh dengan pembahasan berdasarkan antara data, fakta, teori dan temuan-temuan terbaru (jurnal dan paper). Mahasiswa mendiskusikan data yang diperoleh secara kelompok.

Keterampilan berpikir kritis yang terlihat adalah mahasiswa mengumpulkan data, melakukan inferensi, menjelaskan pendapat, serta melakukan analisis. Sedangkan PRB yang terlihat adalah kejujuran dan ketekunan ketika dalam melakukan pengolahan data secara berkelompok. 


\section{Verification base on Religion}

Dosen bersama mahasiswa mendiskusikan integrasi antara topik dengan ayat alQur'an dan hadist yang relevan dengan topik, mengkaji jika ada pertentangan yang muncul antara al-Qur'an dan Hadist terhadap topik Dasar Pewarisan sifat. Mahasiswa memahami konsep, teori, melalui contoh-contoh yang dijumpai dalam kehidupan sehari-hari. Mahasiswa mengkomunikasikan dan mendiskusikan hasil analisis praktikum dengan presentasi perwakilan ke depan kelas (Baqir, 2005).

Keterampilan berpikir kritis mahasiswa yang terlihat adalah diskusi dan tanya jawab ketika pembelajaran di kelas berlangsung. Analisis dan resening (penjelasan).

\section{Generalization \& Awareness}

Mahasiswa menarik kesimpulan dari data, pernyataan, dan pendapat konsep yang dipelajari dengan kerja ilmiah untuk menyusun rekomendasi/tindak lanjut. Mahasiswa menentukan sikap dan tindakan dengan integrasi konsep yang telah dipelajari dengan kajian tinjauan agama dan keterampilan yang dimiliki. Keterampilan berpikir kritis yang terlihat adalah mahasiswa mamapu melakukan self regulation, inferensi, dan mengevaluasi. Mahasiswa mempunyai keyakinan beragama yang lebih kuat sehingga belajar konsep lebih bermakna. Mahasiswa berperilaku sebagai individu atau sebagai anggota masyarakat yg lebih baik (Gamal, 2012)

\section{Keefektifan Model DBUS}

Untuk meningkatkan keterampilan berpikir kritis ditinjau berdasarkan perbandingan nilai gain yang dinormalisasi (N-gain), antara kelompok eksperimen dan kelompok kontrol. Gain yang dinormalisasi (N-gain) dapat dihitung dengan

Tabel dibawah memuat skor rata-rata pre-test dan post-test keterampilan berpikir kritis mahasiswa untuk masing-masing kelas eksperiman.

Berdasarkan Tabel 1, tampak bahwa perbedaan N-gain antara kelompok eksperimen dan kelompok kontrol ketika pembelajaran Dasar Pewarisan Sifat dan Bioteknologi dengan model DBUS. N-gain yang diperoleh kelas eksperimen sebesar 0,23 lebih besar dibandingkan dengan kelompok kontrol sebesar 0,09, sehingga secara umum menggambarkan efektivitas penerapan model DBUS dalam perkuliahan Biologi Umum. 
Tabel 1 Skor dan Hasil Analisis Keterampilan berpikir kritis

\begin{tabular}{|c|c|c|c|c|c|c|c|c|c|}
\hline \multirow[t]{2}{*}{ No } & \multirow[t]{2}{*}{ Konsep } & \multicolumn{4}{|c|}{ Kelas Eksperimen } & \multicolumn{4}{|c|}{ Kelas Kontrol } \\
\hline & & $\mathrm{n}$ & Pretes & Posttes & $\mathrm{N}$-gain & $\mathrm{n}$ & Pretes & Posttes & $\mathrm{N}$-gain \\
\hline \multirow[t]{3}{*}{1} & Dasar & & & & & 101 & 3,168 & 5,0792 & 0,09 \\
\hline & Pewarisan & & & & & & 3 & & \\
\hline & Sifat & & & & & & & & \\
\hline \multirow[t]{2}{*}{2} & & 96 & 2.4583 & 7,4167 & 0,23 & & & & \\
\hline & Bioteknologi & & & & & & & & \\
\hline
\end{tabular}

Hasil pengujian statistik pada Tabel 2 paired sampel test statitistik diperoleh nilai rata-rata pretest adalah 2,45 sedangkan rata-rata nilai posttest 7,4167 adalah Korelasi antara data pretest dan data posttest adalah 0,035 dengan probabilitas 0,035 < $5 \%$, hal ini menunjukan bahwa peningkatan nilai mahasiswa dari pretest ke posttest adalah merata dengan kata lain data pretest memiliki hubungan yang signifikan dengan data posttest. Pada tabel 1 paired sampel test diperoleh nilai $t_{\text {hitung }}=9,326$ dengan nilai $\operatorname{sig} 0,000<0,05$

\section{Tabel 2 paired sampel test}

Paired Samples Test

\begin{tabular}{|l|l|l|l|l|l|l|l|l|}
\hline & & \multicolumn{3}{|l|}{ Paired Differences } & & & \\
& & & & & & \\
& & & & & & \\
Std. \\
\end{tabular}


Dari output model summary, diketahui nilai koefisien determinasi (R Square) sebesar 0,842 (nilai 0,842 adalah pengkuadratan dari koefisien korelasi atau $\mathrm{R}$, yaitu $0,918 \times 0,918=0,842)$. Besarnya angka koefisien determinasi (R Square) 0,842 sama dengan $84,2 \%$

Tabel. 3. Model Hubungan PRB, Keterampilan Berpikir Kritis dan Hasil Kuis

\begin{tabular}{|l|l|l|l|l|l|}
\hline Model & $\mathrm{R}$ & R square & $\begin{array}{l}\text { Adjusted R } \\
\text { Square }\end{array}$ & $\begin{array}{l}\text { Std. Error of } \\
\text { the estimate }\end{array}$ \\
\hline 1. & $.918^{\mathrm{a}}$ & .842 & .807 & 3.421 \\
\hline
\end{tabular}

Angka tersebut mengandung arti bahwa PRB dan Keterampilan berpikir kritis berpengaruh terhadap kemampuan mahasiswa menyelesaikan kuis sebesar 84,2\%. Sedangkan sisanya $(100 \%-84,2 \%=15,8 \%)$ dipengaruhi oleh variabel lain di luar model regresi ini. Besarnya pengaruh variabel lain ini sering disebut sebagai error (e).

\section{SIMPULAN}

Model DBUS diimplementasikan melalui tahapan sintaks yaitu: 1) Stimulation Using Lokal Wisdom, 2) Problem statement 3) Observation and Data Collection 4) Data Processing 5) Verification Bace on Religion 6) Generalization and Warenes.

$\mathrm{N}$-gain yang diperoleh kelas eksperimen sebesar 0,23 lebih besar dibandingkan dengan kelompok kontrol sebesar 0,09, sehingga secara umum menggambarkan efektivitas penerapan model DBUS dalam perkuliahan Biologi Umum.

Hasil pengujian statistik pada Tabel paired sampel test statitistik diperoleh nilai rata-rata pretest adalah 2,45 sedangkan rata-rata nilai posttest 7,4167. Korelasi antara data pretest dan data posttest adalah 0,035 dengan probabilitas 0,035 $<5 \%$, hal ini menunjukan bahwa peningkatan nilai mahasiswa merata dengan kata lain data pretest memiliki hubungan yang signifikan dengan data posttest. Model DBUS dapat memberdayakan PRB dan Keterampilan berpikir kritis mahasiswa dalam mengerjakan kuis sebesar 84,2\%. 


\section{DAFTAR PUSTAKA}

Atilla Cimer, et al. 2015. Crtitical Thinking Level of Biology Classroom survey: Ctlobics. The Online Journal of New Horizons in Education Vol 3. www.tojned.net

Bagir, Zainal Abidin, et al. 2005. Integrasi Ilmu dan Agama Interpretasi dan Aksi, Mizan, Bandung: Mizan

Dracup Mary. 2012. Designing online role plays with a focus on story development to support engagement and critical learning for higher education students. Journal of Learning Design Vol.5

Gamal Abdul Nasir Zakaria and Salwa Mahalle. 2012. Innovation and Creativity in Teaching Islamic Religious Knowlege (IRK) at Secondary Schools in Brunei Darussalam. International Journal of Arts \& Sciences: 5(5):239-252 University Publications. Net

Khasanah N, Sajidan, Sutarno, Baskoro, A.P. 2016. The discovery learning model and the implementation of learning with the unity of sciences in basic biology course to increase critical thinking skills. Proceedings of the Asian Education Symposium 2016 (AES 2016), Bandung, Indonesia, 22-23 November 2016.

Khasanah N, Sajidan, Sutarno, Baskoro, A.P. 2016. The Experiences and Personal Religious Beliefs (PRB) of UIN Walisongo Science Teachers as a Framework for Understanding the Reshaping of their Beliefs and Implementation in Basic Biology Learning. UMRAN-International Journal of Islamic and Civilizational Studies, UTM Malaysia. www.http://jurnalumran.utm.my/index.php/umran

Khasanah N, Sajidan, Sutarno, Baskoro, A.P. 2017. Influence integrated science model and implamantation learning with the unity of science in basic biology course to increase critical thinking. International Journal of Science and Applied Science: Conference Series. UNS

Liliasari. 2007. Scientific Concept and Generic Science Skill Relationship in the $21^{\text {st }}$ Century Science Education. Bandung: SPS UPI

Mansour, N. 2008, The Experiences and Personal Religious Beliefs of Egyptian Science Teachers as a Framework for Understanding the Shaping and Reshaping of their 
Beliefs and Practices about Science-Technology-Society (STS). International Journal of Science Education. Vol. 30, No. 12, 5 October 2008, pp. 1605-1634

Mansour, N. 2009, Science Teachers'Beliefs and Practices: Issues, Implications and Research Agenda, International Journal of Environmental \& Science Education Vol. 4, No. 1: 25-48

Taskın, O. 2014. An exploratory examination of Islamic values in science education: Islamization of science teaching and learning via constructivism. Cult Stud of Sci Education journal, Vol 9:855-875. 